\title{
Review Article \\ Electrospun Nanofibers Containing Strontium for Bone Tissue Engineering
}

\author{
Qi Zhang ${ }^{1},{ }^{1}$ Yanjing Ji, ${ }^{2}$ Weiping Zheng, ${ }^{2}$ Mingzhe Yan, ${ }^{3}$ Danyang Wang, ${ }^{2} \mathrm{Min} \mathrm{Li}^{3}$ \\ Junbo Chen, ${ }^{1}$ Xiao Yan, ${ }^{1}$ Qiang Zhang, ${ }^{1}$ Xiao Yuan $\mathbb{D}^{1,4}$ and Qihui Zhou ${ }^{1,2,3,4}$ \\ ${ }^{1}$ Department of Orthodontics, The Affiliated Hospital of Qingdao University, Qingdao 266003, China \\ ${ }^{2}$ Department of Stomatology, The Affiliated Hospital of Qingdao University, Qingdao 266003, China \\ ${ }^{3}$ Institute for Translational Medicine, Qingdao University, Qingdao 266021, China \\ ${ }^{4}$ School of Stomatology, Qingdao University, Qingdao 266003, China \\ Correspondence should be addressed to Xiao Yuan; yuanxiaoqd@163.com and Qihui Zhou; qihuizhou@qdu.edu.cn
}

Received 26 July 2020; Revised 10 September 2020; Accepted 22 September 2020; Published 24 October 2020

Academic Editor: Xiaoming Li

Copyright ( 2020 Qi Zhang et al. This is an open access article distributed under the Creative Commons Attribution License, which permits unrestricted use, distribution, and reproduction in any medium, provided the original work is properly cited.

Electrospun polymer/metal composite nanofibers have received much attention in the field of bone tissue engineering and regenerative medicine (BTERM) owing to their extracellular matrix- (ECM-) like structure, sufficient mechanical strength, favorable biological properties, and bone induction. In particular, electrospun nanofibers containing strontium (Sr) can significantly promote bone repair and regeneration by mediating osteolysis and osteogenesis, which offers a promising bioactive material for BTERM. In this review, we summarized the effects of electrospun nanofibers containing $\mathrm{Sr}$ on stem cells, osteoblasts, and osteoclasts in BTERM. Also, current challenges and future perspectives for electrospun nanofibers containing Sr in BTERM are briefly outlined. It is hoped that the systematic overview will inspire the readers to further study Sr-containing nanofibers for BTERM and accelerate their translation from the bench to the clinic.

\section{Introduction}

1.1. Bone Defect in Clinical Treatments. Bone is a biological structure that can regenerate by combining with biochemical, cellular, or hormonal processes. The unique structure of natural bone confers excellent mechanical properties, which can support the body, allow movement, protect internal organs, and regulate the storage and release of minerals [1]. Also, bone is a hierarchically structured tissue, mainly composed of organic (30\%) and inorganic (70\%) components. Microscopically, hydroxyapatite (HAp) nanocrystals can be found to be deposited regularly in the collagen interstitial area during bone biomineralization [2]. At the macro level, the bone can be divided into the cortical bone and cancellous bone [3] Cortical bones are mainly distributed in the long bone shaft, commonly with the elastic modulus (17 20 GPa) and compressive strength (131 224 MPa) [4]. In contrast, cancellous bone has a much lower modulus of elasticity because of its high porosity [5]. Therefore, cancellous bone is generally used as a reference to evaluate the mechanical properties of the bone. There are four types of cells in bone tissue: osteogenesis cells, osteoprogenitor cells, osteoblasts, and osteoclasts [6]. Osteoprogenitor cells, as the main cells of bone, can be differentiated into mature bone cells and then further transformed into osteoblasts through activation and proliferation during bone damage and repair. Osteoblasts can produce new bones through osteogenic differentiation, including three stages: proliferation, matrix maturation, and mineralization. The main indicators of osteoblast phenotype are collagen type I, osteopontin $(\mathrm{OPN})$, osteocalcin $(\mathrm{OCN})$, and alkaline phosphatase (ALP) activity detection. Osteoclasts can absorb mineralized bone matrix and degrade collagen, leading to bone destruction or bone absorption [6]. When suffering from severe bone trauma, defects, and tumors, bone grafting is considered as the standard of clinical treatment of bone defects since the bone cannot achieve self-repairing.

Bone tissue engineering and regenerative medicine (BTERM) hold great promise to repair or regenerate bone 
on demand for a higher quality of human life [7-10]. There are three key elements in BTERM, i.e., cells, regulatory factors, and biomaterial scaffolds [11]. Particularly, biomaterials with micro, nano, molecular levels can regulate cell behaviors [12], induce bone formation, and thereby repair or regenerate bone [13-18]. The ideal biomaterial scaffold in BTERM should possess appropriate porosity with a similarity of natural bone structure [19], and excellent pore connectivity with the optimum range of pore size is $200 \sim 350 \mu \mathrm{m}$, which is conducive to cell ingrowth, the nutrient supply, and oxygen transportation. The mechanical property of the scaffold should be maintained in a certain range of Young's modulus to support bone reconstruction and repair activities [20-22]. For instance, the optimal Young's modulus of cortical bone and cancellous bone should be in the range of $15 \sim 20 \mathrm{GPa}$ and $0.1 \sim 2 \mathrm{GPa}$, respectively [23]. Furthermore, it was well demonstrated that the topography and stiffness of bioscaffold have a significant effect on cell adhesion and can maintain the favorable capacities of cell proliferation and differentiation [19, 24-32]. Particularly, ECM-like ultrafine fiber structure has received much attention in the field of BTERM owing to their sufficient mechanical strength, favorable biological properties, and bone induction.

1.2. Nanofibrous Scaffolds in BTERM. While many advanced nanofabrication strategies, e.g., template synthesis, selfassembly, phase separation, and nanoskiving $[33,34]$, have provided useful technologies to prepare ECM-like nanofibers, over the past decade electrospinning has particularly demonstrated its significant impact on the preparation of nanofibers with unique physicochemical properties [35-42] (Figure 1). Electrospinning technology was first invented in 1902 by Cooley and Morton. However, it was not until the past thirty years that the research on the preparation of nanofibers by electrospinning was gradually carried out [43]. The electrospinning technology is to construct an electric field to make the polymer solution electrostatically atomized in the electric field to form a slender fluid and finally form a fiber. A complete electrospinning device consists of a highvoltage power supply, a syringe, a syringe pump, and a metal collector [44]. The fiber diameter can range from micrometer to nanometer level by changing the spinneret, collector, electric field, etc. [45]. At present, electrospinning technology is gradually being used proficiently, and the high-quality polymer nanofiber scaffolds manufactured through it have been recognized in various fields of tissue engineering. In recent years, studies have found that the nanofiber scaffold can imitate the ECM and promote cell proliferation and bone regeneration, due to its advantages of high specific surface area, high porosity, and suitable pore size [46]. Moreover, electrospinning nanofibers can be used as a promising material for drug delivery due to its high loading capacity of drugs, such as antibiotics, proteins, and anticancer drugs [47]. Although advanced fibers are constantly emerging, bone guidance material that can completely replace bone function has not been established clinically. Growth factors are not only expensive but also easily lose activity during processing when incorporated into scaffolds. In contrast, metals play a critical role in the area of biomedicine $[48,49]$ and provide an effec- tive alternative to developing a composite osteoconductive scaffold, which has been proved to be effective in clinical practice [50]. In particular, the past discovered $\mathrm{Sr}$ in bone tissue mineralization is crucial. It is generally believed that $\mathrm{Sr}$ can increase ALP activity and OCN deposition and inhibit osteoclast differentiation $[51,52]$. Therefore, Sr has become a potential additive in BTERM.

1.3. $\mathrm{Sr}$ in BTERM. Sr is one of the trace elements in the human body, most of which are accumulated in bones and teeth after ingestion. Sr has two metabolic effects, i.e., increasing osteoblasts and reducing osteoclast activity [53]. It has been found that adding strontium ions $\left(\mathrm{Sr}^{2+}\right)$ to biomaterials can not only change the porosity and mechanical properties of the fibers but also regulate the metabolism of cells, thereby increasing the healing process of bones [54, 55]. However, long-term and high-dose intake of Sr has side effects, which may lead to rickets [56]. At present, most researches on $\mathrm{Sr}$ in BTERM are doping Sr into composite materials, and there is a lack of further in-depth research on the specific dopant dosage for a certain material to have the best osteogenic effect.

Based on the introduction above, electrospun nanofibers containing strontium (Sr) can significantly promote bone repair and regeneration by mediating osteolysis and osteogenesis, which offers a promising bioactive material for BTERM. We present an overview of the effects of electrospun nanofibers containing $\mathrm{Sr}$ on stem cells, osteoblasts, and osteoclasts. Also, future perspectives for electrospun nanofibers containing Sr in BTERM are briefly outlined.

\section{Sr and Its Properties}

As a nonessential element, Sr accounts for approximately $0.035 \%$ of the skeletal system. Sr is usually captured from food and drinking water, and some foods such as cereals and seafood may contain up to $25 \mathrm{mg} / \mathrm{kg}$ of strontium [57]. $\mathrm{Sr}^{2+}$ has bone-seeking behavior, and studies have shown that bone regeneration can be enhanced when incorporated in synthetic bone grafts. As the size and charge of $\mathrm{Sr}^{2+}$ are very similar to $\mathrm{Ca}^{2+}$, they can displace $\mathrm{Ca}^{2+}$ during osteoblastmediated processes [58]. Researchers have found that $\mathrm{Sr}$ may dually stimulate bone formation by inducing osteoblasts and preventing osteoclast activity [59]. On the one hand, Sr enhances the replication and activity of preosteoblasts, increases the synthesis of bone matrix, and can increase bone formation. On the other hand, Sr can inhibit the differentiation of osteoclasts and induce the apoptosis of osteoclasts to reduce bone resorption [60]. Ca-sensing receptor (CaSR) is a membrane-bound receptor expressed in osteoblasts and osteoclasts. Because $\mathrm{Sr}$ is similar to $\mathrm{Ca}$, Sr mainly acts on CaSR $[61,62]$. Sr not only enhances the proliferation and differentiation of mesenchymal stem cells and osteoblasts but also promotes the mineralization and deposition of extracellular matrix by activating the $\mathrm{Wnt} /$ catenin signaling pathway in the cell [63]. Sr can promote the combination of osteoprotegerin (OPG) and the receptor activator NF- $\kappa \mathrm{B}$ ligand (RANKL), prevent its combination with RANK, and regulate the signaling pathway of osteoclast function to reduce the 


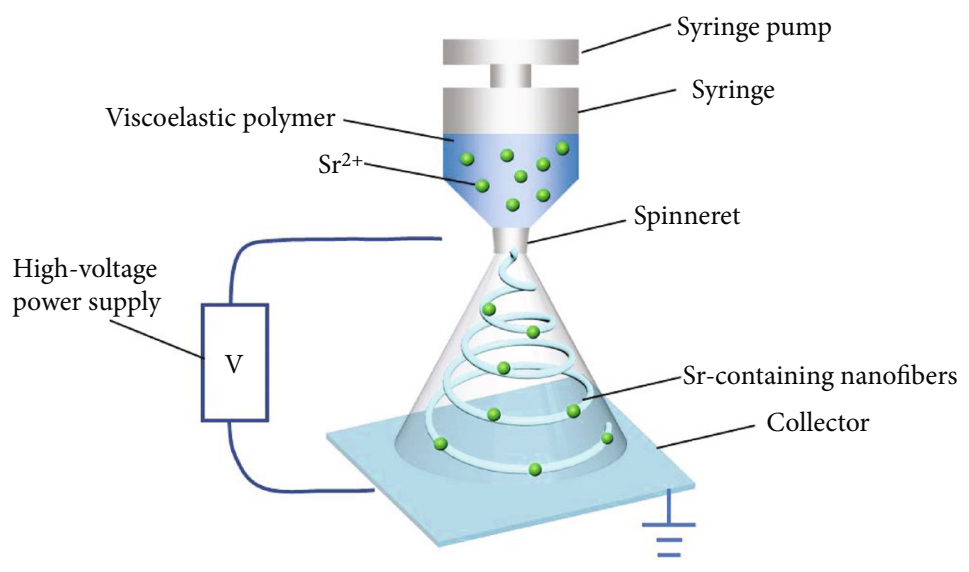

Electrospinning process

FIGURE 1: The schematic diagram of the preparation of electrospun nanofibers containing Sr.

formation of osteoclasts and bone resorption [64]. The mechanism of action of Sr is shown in Figure 2. The dual action has already been under extensive research both in vitro and in vivo. In vitro, $\mathrm{Sr}$ has been proved to promote the osteogenic differentiation of bone mesenchymal stem cells (BMSCs), stimulate the osteoblastic differentiation of human mesenchymal stem cells (hMSCs), increase osteoblast proliferation, reduce osteoblast apoptosis, decrease osteoclast differentiation, and increase osteoclast apoptosis [65]. Sr can also increase bone mass, density, and bone mechanical properties and reduce the risk of the vertebral, nonvertebral, and hip fractures in vivo [66]. Because Sr has a variety of effects on bone physiology, it provides a good treatment strategy for improving the bone-guiding ability of biomaterials to repair and regenerate human damaged lesions. However, it has been reported that there are several long-term side effects when oral Sr-containing drugs have overdosed [67]. Therefore, new methods for targeted delivery of $\mathrm{Sr}^{2+}$ to the defect site are being explored. Several studies report the benefits of combining Sr with polymers to prepare composite scaffolds such as nanofibers for bone tissue engineering [68]. The related research of $\mathrm{Sr}$-containing nanofibers on osteogenesis and osteoclast differentiation in vitro and in vivo experiments is shown in Table 1.

\section{Applications of Sr-Containing Nanofibers in BTERM}

3.1. Sr-Containing Nanofibers and the Osteogenic Differentiation of Stem Cells. Stem cells, such as hMSCs, BMSCs, and SHEDs, are considered as a promising cell source for bone engineering due to their unlimited selfrenewal capacity and multiple differentiation potential [6870]. As a principal player in the regenerative process, ECM provides many biological cues for cell adhesion, proliferation, and differentiation. Along with the similarity to ECM structure, various nanofiber scaffolds can promote the above cell behaviors and even induce the osteogenic differentiation of stem cells by controlling cell morphology. These scaffolds can also be improved by incorporating $\mathrm{Sr}$ nanoparticles which further impart osteogenic characteristics of stem cells by continuously releasing $\mathrm{Sr}^{2+}$ [71]. As a biodegradable polymer, PCL has been widely used in the field of nanofiber spinning production and processing. The nanoscale structure of PCL nanofibers can directly induce bone formation [71] and is particularly suitable for the regeneration of bone tissue around the periosteum, which has been shown to significantly enhance the osseointegration of implants [72]. Meka et al. have studied the growth and osteogenic differentiation of hMSCs on $\mathrm{SrCO}_{3}$-containing PCL nanofibers [69]. The PCL nanofibers containing $20 \% \mathrm{nSrCO}_{3}$ (PCL/SrC20) have been found to promote the proliferation of hMSCs in vitro and significantly increase mineral deposition (up to fourfold), indicating enhanced osteogenesis. Also, the mRNA and protein expression of osteogenic markers (e.g., BMP-2, Osterix, and of Runx2) was increased in PCL/SrC20 composite nanofibers [73-77]. Considering that the diameter, crystallinity, and modulus of PCL/SrC composite scaffolds have little effect, these results may be because the sustained release of $\mathrm{Sr}^{2+}$ stimulates the differentiation of hBMSCs into osteoblasts [78]. Therefore, $\mathrm{nSrCO}_{3}$ can be considered as a nonregulatory growth factor rather than bioactive cues and with a combination of nanofibers is a promising strategy for bone tissue engineering.

As a new source of pluripotent stem cells, SHEDs, which can be differentiated into osteoblasts, have recently attracted much attention [79]. However, limited information is available on the osteogenic potential of SHEDs in Sr-containing artificial nanofibers in vitro. Su et al. have found that both Sr-coated PCL and Sr/PCL blend nanofibers showed significant effects on the osteogenic differentiation of SHEDs in vitro [68]. Cell morphology and MTT analysis showed that these nanofibers effectively support cell attachment and proliferation. Compared with pure PCL nanofibers, PCL nanofibers loaded with $\mathrm{Sr}$ showed better ALP activity, biomineralization, and bone-related gene expression. Though nanofibers imitate ECM architecture and create a suitable microenvironment for cell adhesion, proliferation, 


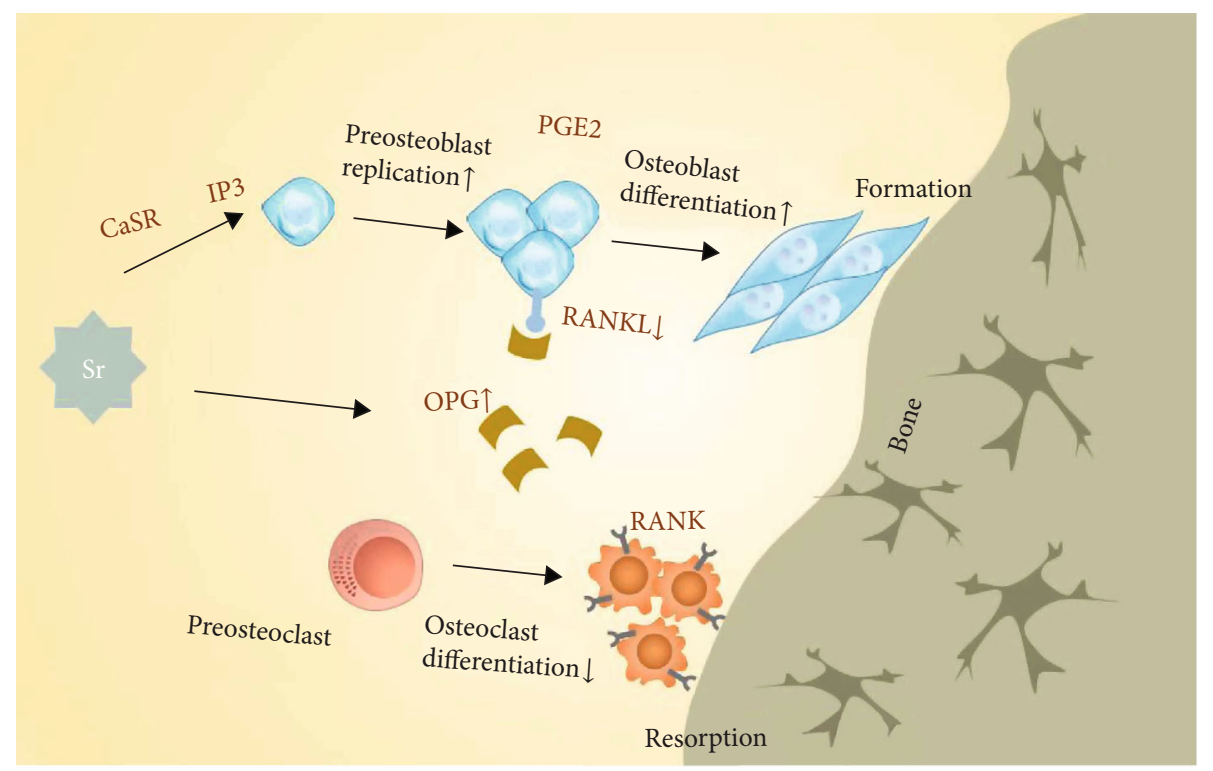

FIGURE 2: Mechanism of Sr at the cellular and molecular level. Sr by activating CaSR to activate 1,4,5-trisphosphate (IP3) to activate osteoblast replication. Sr can also activate osteoblast replication by inducing the expression of cyclooxygenase- (COX-) 2 and prostaglandin 2 (PGE2). For osteoclasts, Sr can increase the bait receptor OPG of RANKL to inhibit RANKL-induced osteoclast formation.

TABLE 1: Sr-containing nanofibers on osteogenesis and osteoclast differentiation in vitro and in vivo experiments.

\begin{tabular}{|c|c|c|c|}
\hline Material & Cell lines/animal model & Results & Ref. \\
\hline $\begin{array}{l}\text { Polycaprolactone (PCL); } \\
\text { Sr/PCL blending; Sr-coated } \\
\text { PCL }\end{array}$ & $\begin{array}{l}\text { Stem cells of human exfoliated } \\
\text { deciduous teeth (SHEDs) }\end{array}$ & $\begin{array}{l}\text { Strontium-loaded PCL nanofibers promote osteogenic } \\
\text { differentiation of SHEDs. }\end{array}$ & [26] \\
\hline PCL; PCL/SrC10; PCL/SrC20 & hMSCs & PCL/SrC20 enhanced proliferation and osteogenesis of hMSCs. & [27] \\
\hline $\begin{array}{l}\text { PLLA; 5Sr/PLLA; 10Sr/PLLA; } \\
\text { 15Sr/PLLA }\end{array}$ & BMSCs/Sprague-Dawley rats & $\begin{array}{l}\text { 15Sr/PLLA promoted cell proliferation and osteogenic } \\
\text { differentiation in vitro and enhanced bone regeneration in vivo. }\end{array}$ & [28] \\
\hline PLLA; PLLA-BBG-Sr & BMSCs & PLLA-BBG-Sr promoted osteogenic differentiation of cells. & [49] \\
\hline $\begin{array}{l}\text { PCL/PLGA-PVA; Sr-coated } \\
\text { PCL/PLGA-PVA }\end{array}$ & MC3T3-E1 & $\begin{array}{l}\text { Sr-coated PCL/PLGA-PVA NFs increased the differentiation of } \\
\text { preosteoblast cells. }\end{array}$ & {$[50]$} \\
\hline PCL; PCL-SrHANF & MG63 osteoblast-like cells & $\begin{array}{l}\text { PCL-SrHANF composite membrane possessed elevated } \\
\text { osteogenic potential. }\end{array}$ & [52] \\
\hline $\begin{array}{l}\text { BGEF; 50Sr-BGNF; } \\
50 \mathrm{Sr} / 0.5 \mathrm{Cu}-\mathrm{BGNF} ; 50 \mathrm{Sr} / 1 \mathrm{Cu}- \\
\text { BGNF }\end{array}$ & $\begin{array}{l}\text { RAW264.7; human vascular } \\
\text { endothelial cells (HUVECs); } \\
\text { hBMSCs }\end{array}$ & $\begin{array}{l}\text { Sr dopant significantly enhanced osteogenesis and suppressed } \\
\text { osteoclastogenesis. }\end{array}$ & [65] \\
\hline
\end{tabular}

and differentiation, their poor mechanical strength still limits their application. By adding Sr coating on PCL or cospinning Sr/PCL nanofiber, Sr-based PCL nanofibers can not only simulate the structure of natural bone but also improve the mechanical properties and biological response of scaffolds [80]. Furthermore, the cell viability of pure PCL and Sr/PCL blended fibers has been significantly higher than that of Srcoated PCL fibers, which may be because of the particles on the surface of strontium phosphate coating that promote cell differentiation and inhibit cell proliferation [81]. This study suggests that $\mathrm{Sr}$ may be a potential inducer for SHED osteogenesis.

Poly-L-lactic acid (PLLA) is a biodegradable and biocompatible polymer, which is widely used in bone tissue engineering and has been approved by the US Federal Food and
Drug Administration (FDA) for clinical applications of a variety of PLLA medical devices [82]. Owing to appropriate flexibility and deformability, PLLA can be processed and manipulated by different techniques (such as fusion, dry and wet spinning, and electrospinning) [36-38, 83, 84]. However, PLLA is generally not considered to be osteoinductive [85]. Experiments by Charles et al. have shown that the introduction of HA into PLLA can improve the interaction between material and bone [86]. Moreover, Han et al. have recently produced Sr/PLLA nanofibers via electrodeposition to study BMSC and nanofiber interaction. The in vitro results revealed that the mineralized Sr/PLLA nanofibers continuously released $\mathrm{Sr}^{2+}$ for controlled times and showed higher release rates of $\mathrm{Ca}^{2+}$ and $\mathrm{PO}_{4}{ }^{3-}$ and excellent ability to promote proliferation and osteogenic differentiation of BMSCs. 
Importantly, in vivo experiments showed that the mineralized Sr/PLLA nanofibers promote bone regeneration. The $\mathrm{Sr}^{2+}$ released from the nanofiber was thought to contribute to enhancing bone repair and regeneration, as shown in Figure 3. Thus, these findings indicate that the mineralization Sr/PLLA nanofibrous membrane has a broad application prospect in bone tissue engineering. Studies have shown that the bioactive glass (BG) can improve the biological performance of PLLA, thereby enhancing its osteoinduction [87]. Fernandes et al. fabricated a composite bioactive glass particle (BBG-Sr) (PLLA-BBG-Sr) by electrospinning [88]. BBG$\mathrm{Sr}$ glass particles are uniformly distributed in PLLA films, thus improving the mechanical properties. The prepared smooth and uniform fibers (width $1 \sim 3 \mu \mathrm{m}$ ) except for BBG-Sr particles $(<45 \mu \mathrm{m})$ have uniform distribution. Moreover, cell evaluation tests of BMSCs showed that PLLA-BBG$\mathrm{Sr}$ membrane enhanced ALP activity and upregulated the expression of osteogenic genes ( $A l p l, S p 7$, and Bglap), which was suggested to promote osteogenic differentiation of BMSCs. These results indicate that the use of this composite material has great potential for promoting bone regeneration.

3.2. Sr-Containing Nanofibers and the Osteogenesis of Osteoblasts. The manufacture of nanofibers with PCL has attracted a lot of attention in tissue engineering. Many studies have shown that adding bioactive substances such as hydroxyapatite (HAp) to PCL can increase the hydrophilicity of PCL. The study found that due to the difference in ionic radius, the solubility of Sr-substituted hydroxyapatite (SrHAp) is higher than that of pure HAp, which contributes to the perturbation of the crystal lattice [89]. Lino et al. found that the proliferation of BMSCs on polydiisopropyl fumarate (PCL-PDIPF) membrane containing 5\% Sr was significantly higher than that on PCL-PDIPF membrane containing 1\% $\mathrm{Sr}$ [90]. Moreover, the replacement of $\mathrm{Ca}^{2+}$ for $\mathrm{Sr}^{2+}$ led to an increase of d-space, and the dissolution of SrHAp increases with the increase of Sr dosage [91]. Tsai et al. produced a bioactive and biodegradable composite film comprising Sr-substituted hydroxyapatite nanofibers (SrHANFs) and PCL and PCL-SrHANF film to evaluate the behavior of osteoblast [92]. The effect of SrHANFs on osteoblast proliferation was not observed in this study. It has been reported that dissolved HAp particles can result in a high local concentration of $\mathrm{Ca}^{2+}$, which may stimulate osteoblast proliferation and immediately switch from stage to stage of differentiation [93]. Lino et al. found that compared with PCL-PDIPF (polydiisopropyl fumarate) membrane containing $1 \% \mathrm{Sr}$, the proliferation of BMSCs on PCL-PDIPF membrane containing $5 \% \mathrm{Sr}$ was higher [90]. Since the difference in ionic radius disturbs the lattice, the dissolution rate of SrHANFs increased with the increase of Sr doping amount [91]. Therefore, the dissolution of SrHANFs may lead to an increase in the concentration of $\mathrm{Ca}^{2+}$ and $\mathrm{Sr}^{2+}$, which affects cell proliferation. The detection of ALP activity, OCN gene expression, and colourimetric calcium quantitative determination showed that the presence of SrHANFs in the PCL membrane promoted the differentiation and activity of osteoblasts, as shown in Figure 4. $\mathrm{Sr}^{2+}$ released from PCLSrHANF membranes may interact with cells via calcium- sensitive receptors ( $\mathrm{CaR}$ ) to activate inositol 1,4,5-triphosphate production and mitogen-activated protein kinase (MAPK) signaling. Thus, the expression and activity of osteogenesis-related genes and proteins are enhanced, and osteogenic differentiation is regulated [94]. By incorporating fragments of $\mathrm{Sr}$-substituted hydroxyapatite nanofibers into PCL, an organic-inorganic composite membrane for guided bone regeneration was first produced. Compared with the PCL membrane alone, PCL-SrHANF composite membrane had higher osteogenesis potential.

Total joint replacement (TJR) surgery is currently one of the most successful functional recovery operations in the clinical practice [95]. However, a major drawback is the lack of early osseointegration of the implant [96]. Electrospun nanofibers can be used as promising implants to improve the deficiency of early osteointegration. Some studies have shown that nanofibers can not only use their structural properties to create an osteogenic environment but also affect the attachment, proliferation, and differentiation of bone cells [97-99]. Previous research by Song et al. showed that in contaminated rat tibial implant models, oxygenated nanofiber coatings can effectively inhibit bacterial infections and enhance osteointegration [96]. These results indicate that these coated nanofibers have great potential to enhance bone integration. Also, nanofibers can be used as a drug delivery device to control release through coaxial electrospinning [100]. Local delivery of $\mathrm{Sr}^{2+}$ from bone substitutes such as nanofibers is considered a promising approach to treat bone defects [78]. In the research of Chen et al., a coaxial PCL/PLGA-PVA nanofiber coating doped with $\mathrm{Sr}^{2+}$ was developed to enhance osseointegration [89]. It was observed from PCL/PLGA-PVA nanofibers that $\mathrm{Sr}^{2+}$ was continuously released for more than two months. SEM images also showed that compared with non- $\mathrm{Sr}^{2+}$-doped nanofibers, $\mathrm{Sr}^{2+}$-doped nanofibers have fewer dense structures and greater porosity. In addition, PCL/PLGA-PVA nanofibers doped with $\mathrm{Sr}^{2+}$ were biocompatible and significantly enhanced the differentiation of murine osteoblast MC3T3-E1 cells through indirect and direct contact methods.

\subsection{Sr-Containing Nanofibers and the Osteolysis of} Osteoclasts. Bioactive glass is a well-known class of synthetic bone replacement materials and has been used clinically for orthopedic and dental applications since 1985 [101]. However, most of the previous bioactive glasses were blockshaped, granular, or fiber-type fused glass with a diameter of hundreds to tens of microns. To stimulate 3D structures and nanofibril structure of bone ECM, some researchers have prepared bioactive glass-based nanofibers by electrospinning and proved their bioactivity by biomineralization of hydroxyapatite crystals in simulated body fluids [102]. Sr can promote the proliferation and differentiation of osteoblasts while reducing the activity of osteoclasts [103]. Inspired by these results, researchers have incorporated $\mathrm{Sr}$ into a variety of calcium phosphate and porous bioactive glass to induce bone regeneration through the long-term release of $\mathrm{Sr}^{2+}$. Wen et al. produced microactive glass nanofibers doped with $\mathrm{Sr}$ and $\mathrm{Cu}$, and the released ions affected the viability and cell function of related cell types [104]. The 


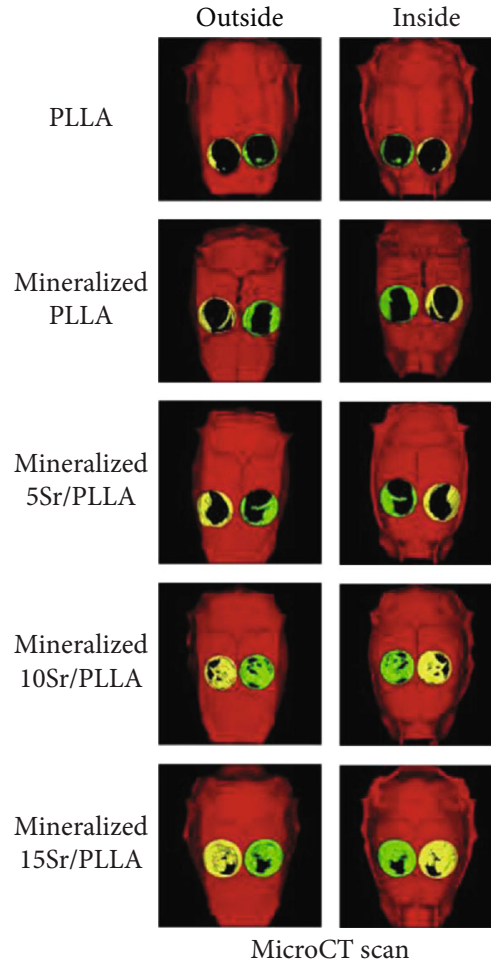

(a)

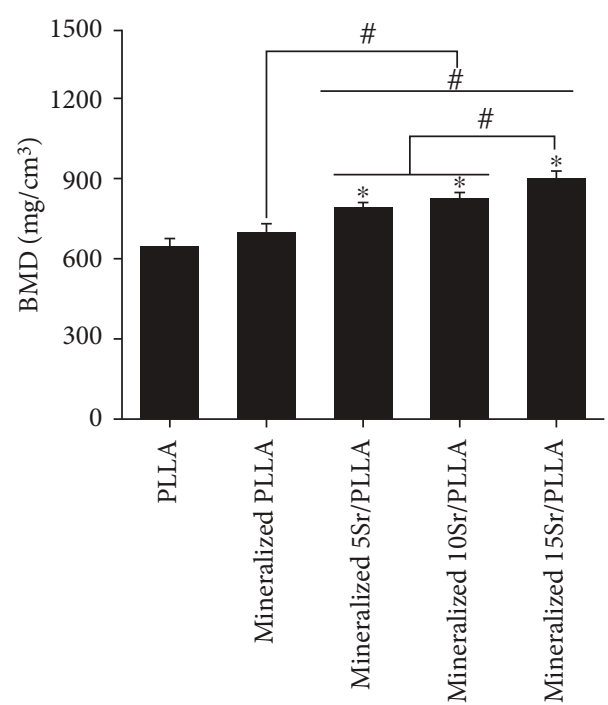

(c)

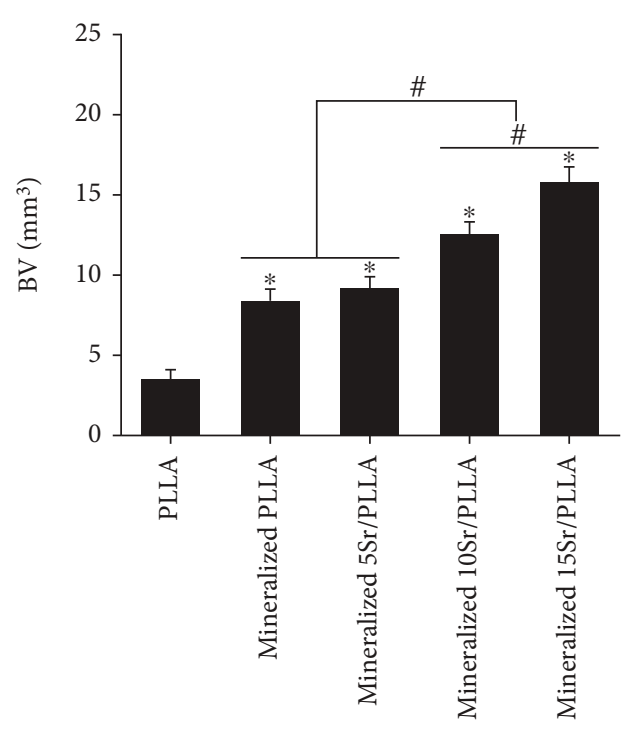

(b)

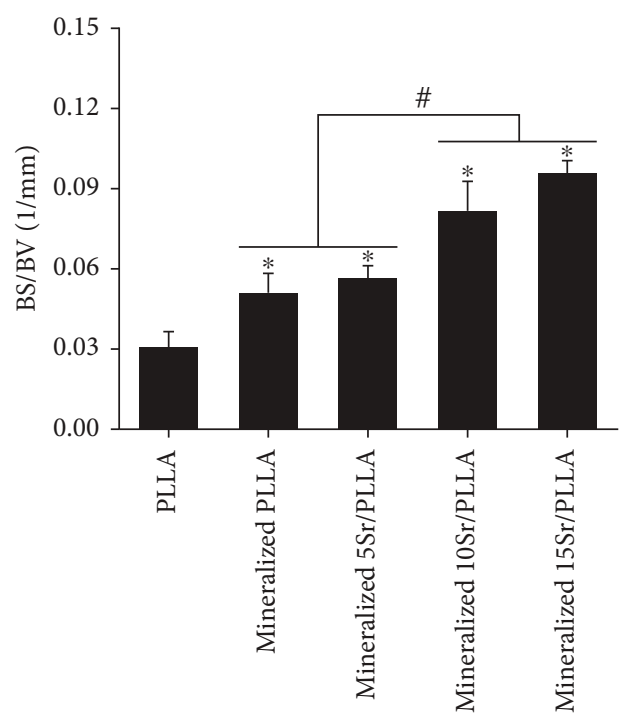

(d)

Figure 3: Continued. 


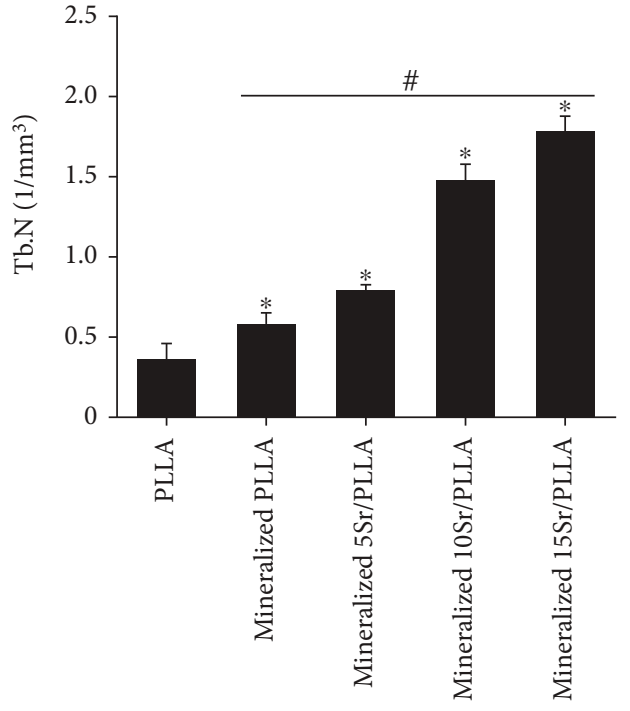

(e)

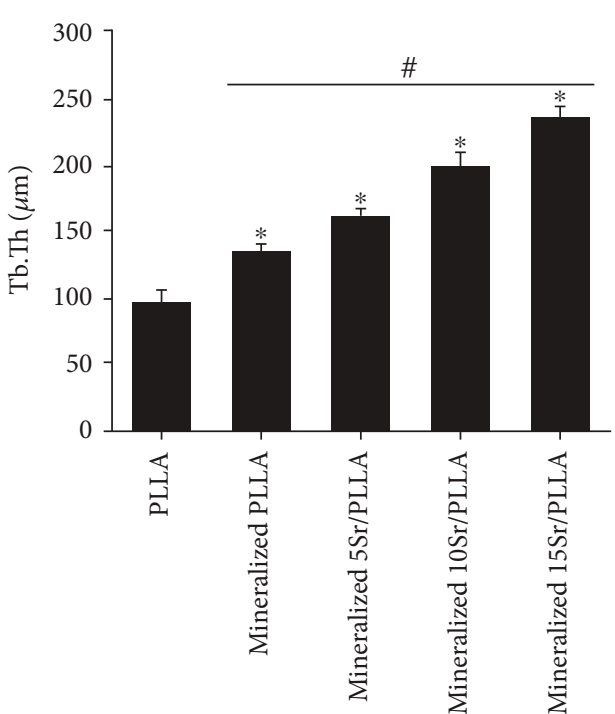

(f)

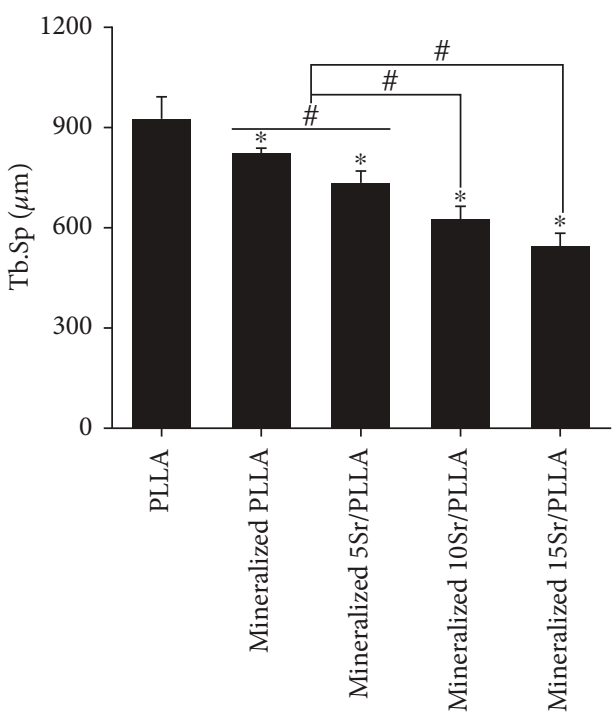

(g)

FIGURE 3: In vivo experiments of nanofibers with different $\mathrm{Sr}$ content induced bone formation. With the increase of Sr content, the osteogenic effect became stronger [60].

diameter of bioactive glass fiber can be increased by adding $\mathrm{Sr}$ instead of $\mathrm{Ca}$. The reason may be that the conductivity of $\mathrm{Sr}^{2+}$ is lower than that of $\mathrm{Ca}^{2+}$, which may cause the current of glass fibers with dopants to decrease during the electric discharge process and eventually make the diameter of the electric discharge nanofibers smaller [105]. These findings indicate that the properties of dopant or substituent ions play a critical role in controlling fiber diameter. By studying the release of therapeutic ions from the doped glass nanofibers into the cell culture medium, it was found that $\mathrm{Sr}^{2+}$ showed a rapid burst release during the first $120 \mathrm{~h}$, followed by constant release kinetics. The accelerated release may be due to the fact that dopant $\mathrm{Sr}^{2+}$ has a higher solubility [106]. The artificial Sr-containing bioactive glass fibers immersed in simulated body fluid (SBF) accelerated the formation of apatite crystals. According to previous reports, the surfaces of $\mathrm{Sr}$ - doped bioactive glass and Sr-doped HAp mineralized electrospun polymer nanofibers are smoother, making them a less preferred formation of apatite nuclear sites [106]. TRAP analysis is a marker of osteoclast differentiation and bone resorption activity. Through this analysis, the effect of $\mathrm{Sr}$ released from bioactive glass nanofibers on the differentiation and maturation of RAW264.7 macrophages into multinuclear osteoclasts was studied. Quantitative comparison of the number of TRAP-positive macrophages obtained from the solution extracted from Sr-doped bioactive glass nanofibers with RAW264.7 cells treated with lipopolysaccharide (LPS) showed that osteoclast activity was inhibited, as shown in Figure 5 [107]. Few studies illustrate $\mathrm{Sr}^{2+}$ inhibitory effect on bone resorption. The molecular basis of this antiosteoclast effect induced by Sr revolves around the RANKL signaling pathway. Sr promoted OPG in conjunction with the relevant 


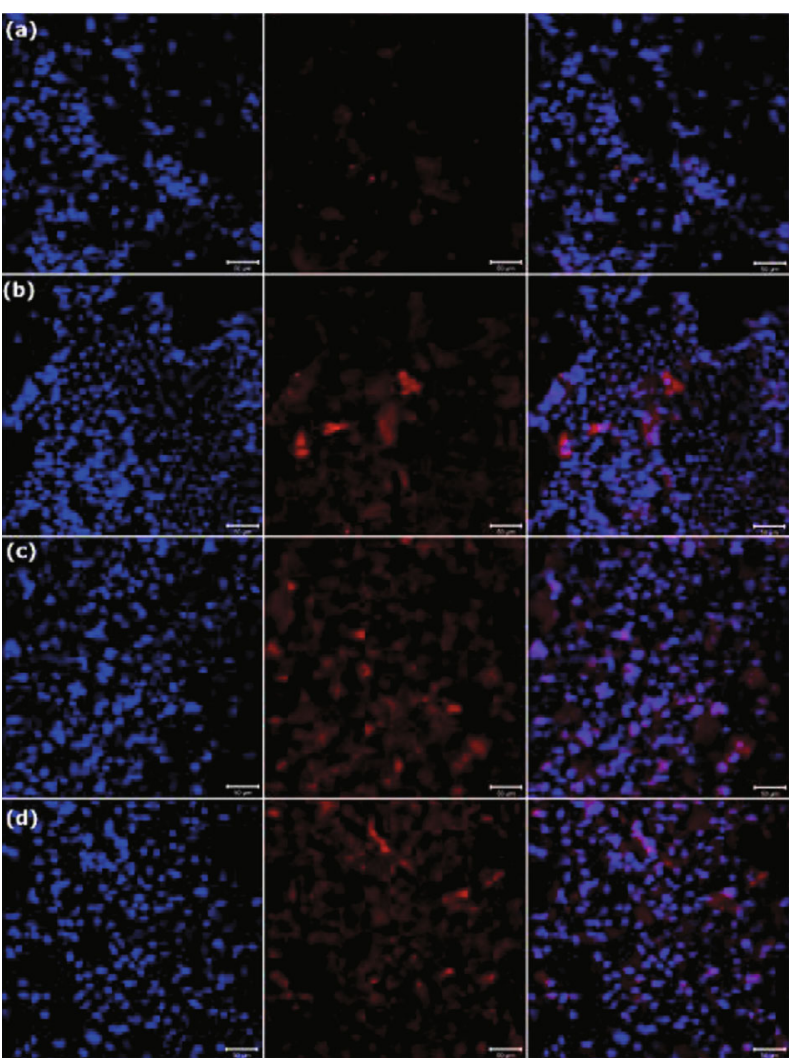

(a)

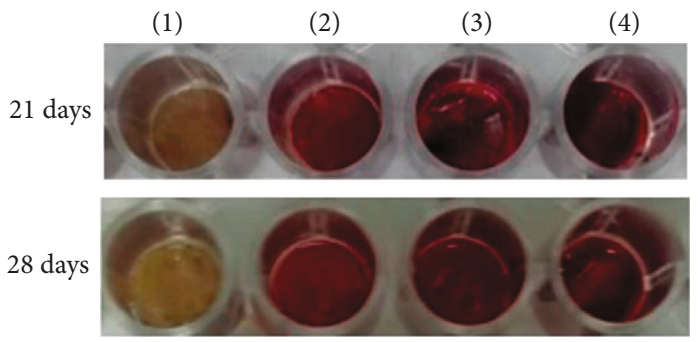

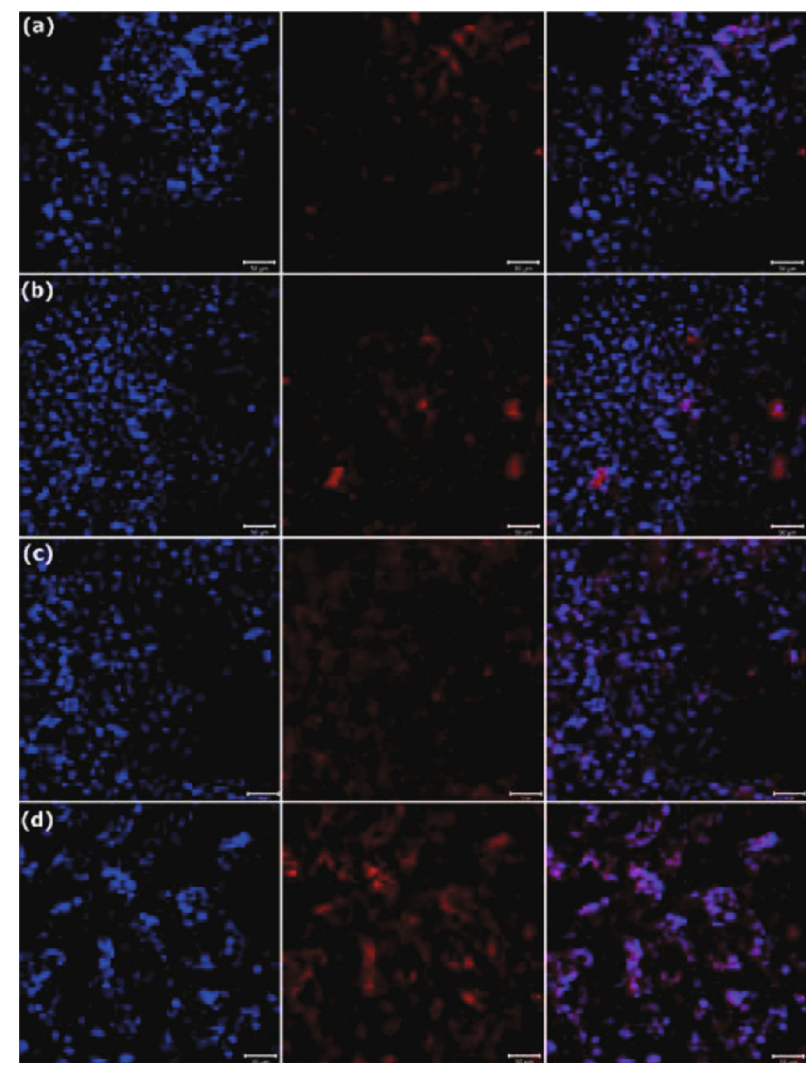

(b)

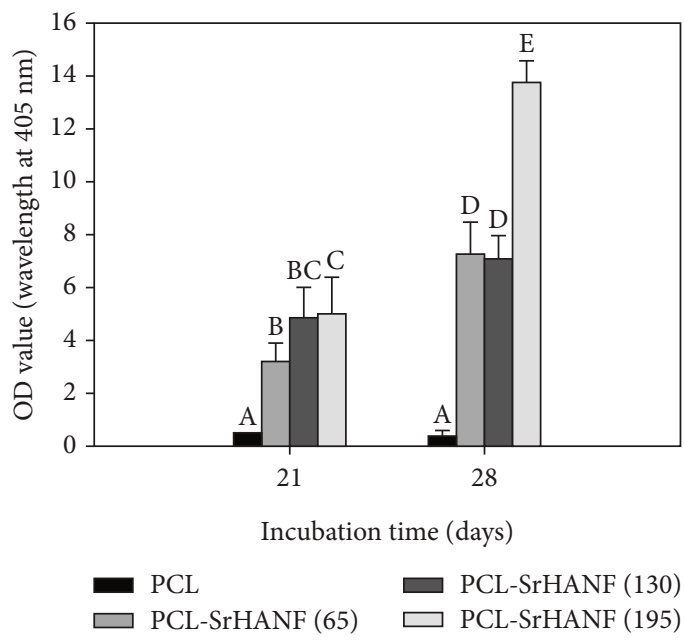

(d)

FIGURE 4: (a, b) BSP and OCN protein immunofluorescence staining of MG63 osteoblast-like cells on (A) PCL, (B) PCL-SrHANF (65), (C) PCL-SrHANF (130), and (D) PCL-SrHANF (195) after 14 days of culture. (c) Optical images by Alizarin Red-S (ARS) staining. (d) ARS staining for quantitative analysis of mineral deposits [82].

RANKL and prevented it from binding to RANK [64]. Therefore, $\mathrm{Sr}^{2+}$ has a direct impact on the RANK/RANKL/OPG systems and is a key factor for bone remodeling and homeostasis. However, moderate-high concentrations of $\mathrm{Sr}^{2+}$ are required to produce this osteoclast-resistant effect. In previous studies, low concentrations (about $200 \mathrm{ppb}$ ) of $\mathrm{Sr}^{2+}$ released from $\beta$-tricalcium phosphate (Sr-doped $\beta$ TCP) bioceramics did not prevent RAW 264.7 mononuclear osteoclastogenesis to mature osteoclasts [108]. In contrast, in the study by Wen et al., the lever of $\mathrm{Sr}^{2+}$ in the extraction medium from the doped bioactive glass nanofibers was high enough (about 0.3-0.4 mM) to sufficiently inhibit the activity of osteoclasts [104]. In short, Sr-doped bioactive glass nanofibers prepared by electrospinning accelerated the formation of apatite crystals on the surface when immersed in SBF. Ion release kinetics showed that $\mathrm{Sr}^{2+}$ was continuously released during the test period, and $\mathrm{Sr}$ dopants significantly increased osteogenesis and inhibited osteoclastogenesis. 


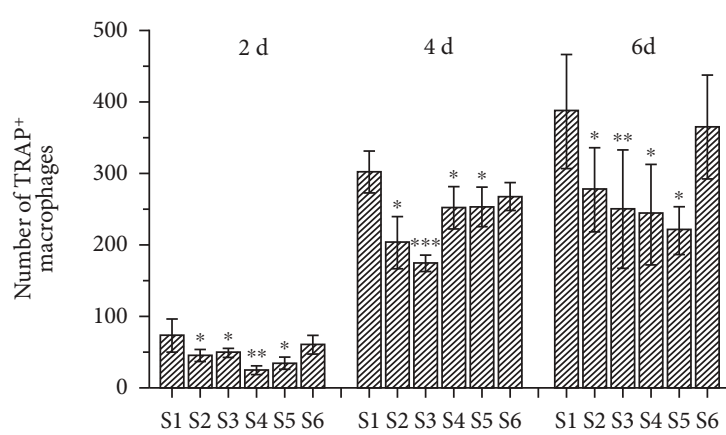

(a)

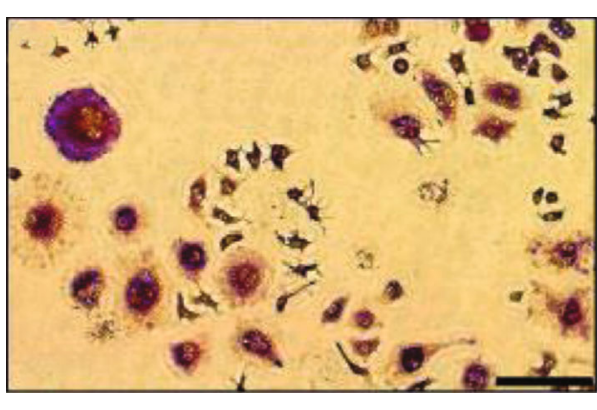

(b)

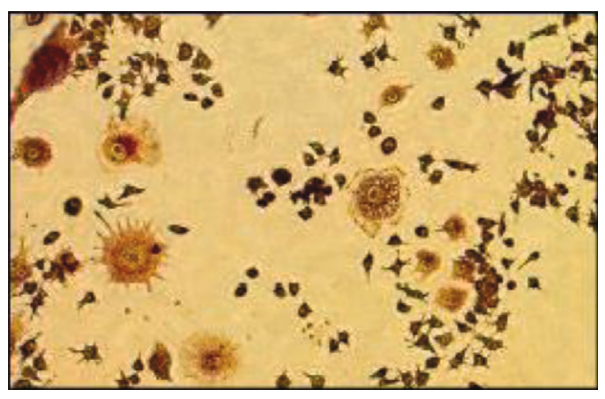

(c)

FIGURE 5: All groups containing released $\mathrm{Sr}^{2+}$ showed inhibition of osteoclast activity [94].

3.4. Sr-Containing Nanofibers with Antibacterial Properties and Drug Delivery. Nanofiber-structured bioactive materials have excellent potential for use as bone defect fillers because they can mimic the architecture of the ECM. On this basis, endowing implants with antibacterial properties can prevent or treat implant-related infections. Bioactive glass is one of the suitable choices for antibacterial properties, depending on the composition, the concentration of the glass, the microorganisms, and their morphology [109]. In a recent study, two different components of bioactive glass nanofibers, M1/45 (45S5 Bioglass ${ }^{\circledR}$ ) and ICIE 16M (bioactive glass doped with $\mathrm{Zn}$ and $\mathrm{Sr}$ ), were produced using laser spinning technology to test antibacterial activity against Staphylococcus aureus $[110,111]$. The release of $\mathrm{Zn}^{2+}$ and $\mathrm{Sr}^{2+}$ demonstrated the additional bactericidal effect of doped nanofibers for longer periods. $\mathrm{ZnO}$ and $\mathrm{SrO}$ may also be doped into the nanostructure as a network modifier, like the alkali metal oxide glass [112]. The difference of density between two types of laser-spun glass nanofibers indicates that $\mathrm{Zn}^{2+}$ and $\mathrm{Sr}^{2+}$ doped nanofibers formed a more closed structure, which limits the infiltration of the medium, thus slowing down the dissolution of the nanofibers. As a result, its biological activity is affected. The decrease in the release rate of potentially toxic ions may also affect the effectiveness of nanofibers against bacteria.

As an effective drug delivery system, nanofibers have attracted much attention as mesoporous materials due to their excellent drug loading capacity and drug release efficacy and have become drug delivery systems $[113,114]$. In a previous work, Tsai et al. prepared mesoporous hydroxyapatite$\mathrm{CaO}$ composite nanofibers ( $\mathrm{p}-\mathrm{HapFs}$ ) and found that $\mathrm{p}$ HapFs have good drug-loading efficiency and can delay the burst release of tetracycline (TC). However, many studies have shown that $\mathrm{CaO}$ plays a negative role in the biocompatibility of HAp $[115,116]$. Kanchana and Sekar found that the addition of Sr during the synthesis of biphasic calcium phosphate using the sol-gel method can reduce the formation of $\mathrm{CaO}$ impurities [117]. In another study, Sr-substituted hydroxyapatite- $\mathrm{CaO}-\mathrm{CO}_{3}$ nanofibers (mSrHANFs) with the mesoporous structure were prepared and characterized by electrospinning, and the effects of different doping amounts on the composition of mSrHANFs were evaluated [91]. TC was selected to evaluate the drug-loading efficiency, drug release mechanism, and antibacterial activity of the model drug. It was found that as the doping amount of Sr increased, the content of $\mathrm{CaO}$ and $\mathrm{CaCO}_{3}$ in the sample decreased. The mSrHANFs showed excellent drug-loading efficiency and TC sustained-release capacity for more than 3 weeks, which maintained the antibacterial activity well, as shown in Figure 6.

\section{Conclusion and Future Perspectives}

This review summarizes some insights on the effect of Srcontaining nanofibers in bone tissue engineering. Srcontaining nanofibers have not only good potential to imitate natural bone ECM but also special effects on cell growth and differentiation, which provides a new strategy for bone tissue regeneration and repair. Sr dopants have been confirmed that can enhance the osteogenic effect and inhibit the formation of osteoclasts. Also, the use of Sr nanoparticles can replace the biofunctionalization of biomolecules for bone tissue engineering. Sr-containing nanofibers have proved to have excellent biocompatibility with bone tissue, promote the growth of seed cells and osteogenic differentiation, were used for drug delivery in bone regeneration engineering, and have excellent 


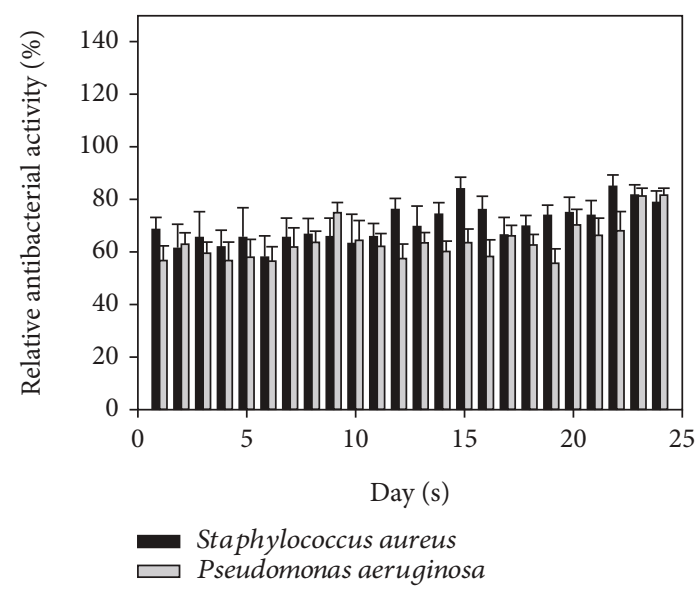

FIgURE 6: The solution obtained with 3mSrHANFs loaded with TC can effectively delay the growth of bacteria to day 24 [81].

antibacterial effects. Moreover, Sr-containing nanofibers have excellent drug-loading efficiency, which can delay the burst release of drugs and can continuously release drugs locally, which is very ideal for transplants. The inclusion of $\mathrm{Sr}^{2+}$ in the nanofiber structure leads to changes in its dissolution kinetics, and the Sr-doped nanofibers show an additional bactericidal effect for a longer period. Such hybrid scaffolds with multifunctional elements that perform complementary functions are promising for the development of tissue substitutes.

Electrospinning nanofibers have broad prospects for development, because they can process various polymer materials to stimulate the hierarchical structure of ECM, which is conducive to cell infiltration and survival. Recent studies have shown that Sr-containing nanofibers can promote the differentiation of human osteoprogenitor cells into osteocytes. The future development direction of this field is to manufacture scaffolds with mechanical properties comparable to those of natural bone. Sr-containing nanofibers have become a hot spot in BTERM research in recent years. Most studies have confirmed that the incorporation of Sr can effectively improve the mechanical properties of nanofibers, improve the differentiation ability of osteoblasts, and promote the ability of bone formation in vivo. However, different researchers use different $\mathrm{Sr}$ doping methods, and the results of the research and the optimal Sr doping concentration are not consistent. With the deepening of its research, as an emerging tissue engineering material, Sr-containing nanofibers are expected to become an ideal artificial bone substitute material in the field of bone tissue repair.

\section{Data Availability}

The data used to support the findings of this study are available from the corresponding authors upon request.

\section{Conflicts of Interest}

The authors declare no conflict of interest.

\section{Acknowledgments}

The authors are very grateful for the financial support of the National Natural Science Foundation of China (Grant Nos. 31900957 and 31870929), Shandong Provincial Natural Science Foundation (Grant Nos. ZR2019QC007 and ZR2019MH007), Innovation and Technology Program for the Excellent Youth Scholars of Higher Education of Shandong Province (Grant No. 2019KJE015), China Postdoctoral Science Foundation (Grant No. 2019M652326), and Scientific Research Foundation of Qingdao University (Grant No. DC1900009689).

\section{References}

[1] Y. Liu, D. Luo, and T. Wang, "Hierarchical structures of bone and bioinspired bone tissue engineering," Small, vol. 12, no. 34, pp. 4611-4632, 2016.

[2] Z. Hao, Z. Song, J. Huang et al., "The scaffold microenvironment for stem cell based bone tissue engineering," Biomaterials Science, vol. 5, no. 8, pp. 1382-1392, 2017.

[3] N. Reznikov, R. Shahar, and S. Weiner, "Bone hierarchical structure in three dimensions," Acta Biomaterialia, vol. 10, no. 9, pp. 3815-3826, 2014.

[4] R. Hodgskinson and J. D. Currey, "Young's modulus, density and material properties in cancellous bone over a large density range," Journal of Materials Science. Materials in Medicine, vol. 3, no. 5, pp. 377-381, 1992.

[5] J. R. Porter, T. T. Ruckh, and K. C. Popat, "Bone tissue engineering: a review in bone biomimetics and drug delivery strategies," Biotechnology Progress, vol. 25, no. 6, pp. 15391560, 2009.

[6] M. Doblaré, J. M. García, and M. J. Gómez, "Modelling bone tissue fracture and healing: a review," Engineering Fracture Mechanics, vol. 71, no. 13-14, pp. 1809-1840, 2004.

[7] Y. Li, Y. Xiao, and C. Liu, "The horizon of materiobiology: a perspective on material-guided cell behaviors and tissue engineering," Chemical Reviews, vol. 117, no. 5, pp. 4376-4421, 2017.

[8] G. Huang, F. Li, X. Zhao et al., "Functional and biomimetic materials for engineering of the three-dimensional cell microenvironment," Chemical Reviews, vol. 117, no. 20, pp. 12764-12850, 2017.

[9] C. Wang, G. Cao, T. Zhao et al., "Terminal group modification of carbon nanotubes determines covalently bound osteogenic peptide performance," ACS Biomaterials Science \& Engineering, vol. 6, no. 2, pp. 865-878, 2020.

[10] B. Pei, W. Wang, N. Dunne, and X. Li, "Applications of carbon nanotubes in bone tissue regeneration and engineering: superiority, concerns, current advancements, and prospects," Nanomaterials, vol. 9, no. 10, article 1501, 2019.

[11] M. R. Iaquinta, E. Mazzoni, M. Manfrini et al., "Innovative biomaterials for bone regrowth," International Journal of Molecular Sciences, vol. 20, no. 3, p. 618, 2019.

[12] S. Wang, X. Yang, L. Zhou, J. Li, and H. Chen, "2D nanostructures beyond graphene: preparation, biocompatibility and biodegradation behaviors," Journal of Materials Chemistry B, vol. 8, no. 15, pp. 2974-2989, 2020.

[13] M. M. Stevens, "Biomaterials for bone tissue engineering," Materials Today, vol. 11, no. 5, pp. 18-25, 2008.

[14] Q. Zhou, J. Chen, Y. Luan et al., "Unidirectional rotating molecular motors dynamically interact with adsorbed 
proteins to direct the fate of mesenchymal stem cells," Science Advances, vol. 6, article eaay2756, no. 5, 2020.

[15] Z. P. Du, X. X. Feng, G. X. Cao et al., "The effect of carbon nanotubes on osteogenic functions of adipose-derived mesenchymal stem cells in vitro and bone formation in vivo compared with that of nano-hydroxyapatite and the possible mechanism," Bioactive Materials, vol. 6, no. 2, pp. 333-345, 2021.

[16] T. Mokabber, Q. Zhou, A. I. Vakis, P. van Rijn, and Y. T. Pei, "Mechanical and biological properties of electrodeposited calcium phosphate coatings," Materials Science and Engineering: $C$, vol. 100, pp. 475-484, 2019.

[17] X. Bi, L. Li, Z. Mao et al., "The effects of silk layer-by-layer surface modification on the mechanical and structural retention of extracellular matrix scaffolds," Biomaterials Science, vol. 8, no. 14, pp. 4026-4038, 2020.

[18] W. Wang, Z. Wang, Y. Fu et al., "Improved osteogenic differentiation of human amniotic mesenchymal stem cells on gradient nanostructured Ti surface," Journal of Biomedial Materials Research Part A, vol. 108, no. 9, pp. 1824-1833, 2020.

[19] A. Przekora, "The summary of the most important cellbiomaterial interactions that need to be considered during in vitro biocompatibility testing of bone scaffolds for tissue engineering applications," Materials Science and Engineering: C, vol. 97, pp. 1036-1051, 2019.

[20] L. Wang, C. Wang, S. Wu, Y. Fan, and X. Li, "Influence of the mechanical properties of biomaterials on degradability, cell behaviors and signaling pathways: current progress and challenges," Biomaterials Science, vol. 8, no. 10, pp. 2714-2733, 2020.

[21] L. Wang, S. Wu, G. Cao, Y. Fan, N. Dunne, and X. Li, "Biomechanical studies on biomaterial degradation and co-cultured cells: mechanisms, potential applications, challenges and prospects," Journal of Materials Chemistry B, vol. 7, no. 47, pp. 7439-7459, 2019.

[22] K. Zhang, X. Xiao, X. Wang, Y. Fan, and X. Li, “Topographical patterning: characteristics of current processing techniques, controllable effects on material properties and cocultured cell fate, updated applications in tissue engineering, and improvement strategies," Journal of Materials Chemistry $B$, vol. 7, no. 45, pp. 7090-7109, 2019.

[23] S. Bose, M. Roy, and A. Bandyopadhyay, "Recent advances in bone tissue engineering scaffolds," Trends in Biotechnology, vol. 30, no. 10, pp. 546-554, 2012.

[24] G. R. Liguori, Q. Zhou, T. T. A. Liguori et al., "Directional topography influences adipose mesenchymal stromal cell plasticity: prospects for tissue engineering and fibrosis," Stem Cells International, vol. 2019, Article ID 5387850, 14 pages, 2019.

[25] P. T. Kühn, Q. Zhou, T. A. B. van der Boon, A. M. SchaapOziemlak, T. G. van Kooten, and P. van Rijn, "Double linear gradient biointerfaces for determining two-parameter dependent stem cell behavior," ChemNanoMat, vol. 2, no. 5, pp. 407-413, 2016.

[26] Q. Zhou, L. Ge, C. F. Guimarães, P. T. Kühn, L. Yang, and P. van Rijn, "Development of a novel orthogonal double gradient for high-throughput screening of mesenchymal stem cells-materials interaction," Advanced Materials Interfaces, vol. 5, no. 18, article 1800504, 2018.

[27] Q. Zhou, P. Wünnemann, P. T. Kühn et al., "Mechanical properties of aligned nanotopologies for directing cellular behavior," Advanced Materials Interfaces, vol. 3, no. 18, article 1600275, 2016.
[28] Q. Zhou, O. Castañeda Ocampo, C. F. Guimarães, P. T. Kühn, T. G. van Kooten, and P. van Rijn, "Screening platform for cell contact guidance based on inorganic biomaterial micro/nanotopographical gradients," ACS Applied Materials \& Interfaces, vol. 9, no. 37, pp. 31433-31445, 2017.

[29] A. M. Almonacid Suarez, Q. Zhou, P. van Rijn, and M. C. Harmsen, "Directional topography gradients drive optimum alignment and differentiation of human myoblasts," Journal of Tissue Engineering and Regenerative Medicine, vol. 13, no. 12, pp. 2234-2245, 2019.

[30] Q. Zhou, P. T. Kühn, T. Huisman et al., "Directional nanotopographic gradients: a high-throughput screening platform for cell contact guidance," Scientific Reports, vol. 5, no. 1, article 16240, 2015.

[31] X. Qiu, S. Xu, Y. Hao et al., "Biological effects on tooth root surface topographies induced by various mechanical treatments," Colloids Surfaces B Biointerfaces, vol. 188, article 110748, 2020

[32] Y. Hao, W. Zhao, L. Zhang et al., "Bio-multifunctional alginate/chitosan/fucoidan sponges with enhanced angiogenesis and hair follicle regeneration for promoting full-thickness wound healing," Materials and Design, vol. 193, article 108863, 2020.

[33] Q. Zhou, Z. Zhao, Z. Zhou, G. Zhang, R. C. Chiechi, and P. van Rijn, "Directing mesenchymal stem cells with gold nanowire arrays," Advanced Materials Interfaces, vol. 5, no. 14, article 1800334, 2018.

[34] Kenry and C. T. Lim, "Nanofiber technology: current status and emerging developments," Progress in Polymer Science, vol. 70, pp. 1-17, 2017.

[35] Y. Zhang, C. T. Lim, S. Ramakrishna, and Z. M. Huang, "Recent development of polymer nanofibers for biomedical and biotechnological applications," Journal of Materials Science Materials in Medicine, vol. 16, no. 10, pp. 933-946, 2005.

[36] H. Yuan, Q. Zhou, B. Li, M. Bao, X. Lou, and Y. Zhang, "Direct printing of patterned three-dimensional ultrafine fibrous scaffolds by stable jet electrospinning for cellular ingrowth," Biofabrication, vol. 7, no. 4, article 045004, 2015.

[37] Q. Zhou, J. Xie, M. Bao et al., "Engineering aligned electrospun PLLA microfibers with nano-porous surface nanotopography for modulating the responses of vascular smooth muscle cells," Journal of Materials Chemistry B, vol. 3, no. 21, pp. 4439-4450, 2015.

[38] Q. Zhou, M. Bao, H. Yuan, S. Zhao, W. Dong, and Y. Zhang, "Implication of stable jet length in electrospinning for collecting well-aligned ultrafine PLLA fibers," Polymer, vol. 54, no. 25, pp. 6867-6876, 2013.

[39] Q. Zhou, H. Zhang, Y. Zhou et al., "Alkali-mediated miscibility of gelatin/polycaprolactone for electrospinning homogeneous composite nanofibers for tissue scaffolding," Macromolecular Bioscience, vol. 17, article 1700268, 2017.

[40] M. Bao, X. Lou, Q. Zhou, W. Dong, H. Yuan, and Y. Zhang, "Electrospun biomimetic fibrous scaffold from shape memory polymer of PDLLA-co-TMC for bone tissue engineering," ACS Applied Materials \& Interfaces, vol. 6, no. 4, pp. 2611-2621, 2014.

[41] S. Zhao, Q. Zhou, Y.-Z. Long, G.-H. Sun, and Y. Zhang, "Nanofibrous patterns by direct electrospinning of nanofibers onto topographically structured non-conductive substrates," Nanoscale, vol. 5, no. 11, pp. 4993-5000, 2013.

[42] H. Yuan, Q. Zhou, and Y. Zhang, "6 - Improving fiber alignment during electrospinning," in Electrospun Nanofibers, 
Series in Textiles, M. B. T.-E. N. Afshari, Ed., pp. 125-147, Woodhead Publishing, 2017.

[43] J. Doshi and D. H. Reneker, "Electrospinning process and applications of electrospun fibers," Journal of Electrostatics, vol. 35, no. 2-3, pp. 151-160, 1995.

[44] H. Fong and D. H. Reneker, "Electrospinning and the formation of nanofibers," in Structure Formation in Polymeric Fibers, pp. 225-246, Hanser, 1999.

[45] P. Ramesh Kumar, N. Khan, S. Vivekanandhan, N. Satyanarayana, A. K. Mohanty, and M. Misra, "Nanofibers: effective generation by electrospinning and their applications," Journal of Nanoscience and Nanotechnology, vol. 12, no. 1, pp. 1-25, 2012.

[46] K. Kalantari, A. M. Afifi, H. Jahangirian, and T. J. Webster, "Biomedical applications of chitosan electrospun nanofibers as a green polymer - review," Carbohydrate Polymers, vol. 207, pp. 588-600, 2019.

[47] Y. Lu, J. Huang, G. Yu et al., "Coaxial electrospun fibers: applications in drug delivery and tissue engineering," Wiley Interdisciplinary Reviews: Nanomedicine and Nanobiotechnology, vol. 8, no. 5, pp. 654-677, 2016.

[48] L. Zhou, J. Zhao, Y. Chen et al., "MoS2-ALG-Fe/GOx hydrogel with Fenton catalytic activity for combined cancer photothermal, starvation, and chemodynamic therapy," Colloids Surfaces B Biointerfaces, vol. 195, article 111243, 2020.

[49] K. Luo, J. Zhao, C. Jia et al., "Integration of $\mathrm{Fe}_{3} \mathrm{O}_{4}$ with $\mathrm{Bi}_{2} \mathrm{~S}_{3-}$ for multi-modality tumor theranostics," ACS Applied Materials \& Interfaces, vol. 12, no. 20, pp. 22650-22660, 2020.

[50] A. Matsumoto, "Effect of strontium on the epiphyseal cartilage plate of rattibiae-histological and radiographic studies," $\Theta \eta \sigma \alpha v \rho i \sigma \mu \alpha \tau \alpha$, vol. 13, pp. 258-283, 1976.

[51] O. Z. Andersen, V. Offermanns, M. Sillassen et al., "Accelerated bone ingrowth by local delivery of strontium from surface functionalized titanium implants," Biomaterials, vol. 34, no. 24, pp. 5883-5890, 2013.

[52] C.-J. Chung and H.-Y. Long, "Systematic strontium substitution in hydroxyapatite coatings on titanium via micro-arc treatment and their osteoblast/osteoclast responses," Acta Biomaterialia, vol. 7, no. 11, pp. 4081-4087, 2011.

[53] C. B. Tovani, T. M. Oliveira, A. Gloter, and A. P. Ramos, "Sr2 +-substituted $\mathrm{CaCO}_{3}$ nanorods: impact on the structure and bioactivity," Crystal Growth \& Design, vol. 18, no. 5, pp. 2932-2940, 2018.

[54] R. J. Kavitha, K. Ravichandran, and T. S. N. Sankara Narayanan, "Deposition of strontium phosphate coatings on magnesium by hydrothermal treatment: characteristics, corrosion resistance and bioactivity," Journal of Alloys and Compounds, vol. 745, pp. 725-743, 2018.

[55] S. Peng, X. S. Liu, S. Huang et al., "The cross-talk between osteoclasts and osteoblasts in response to strontium treatment: involvement of osteoprotegerin," Bone, vol. 49, no. 6, pp. 1290-1298, 2011.

[56] H. Y. Lee, D. Lie, K. S. Lim, T. Thirumoorthy, and S. M. Pang, "Strontium ranelate-induced toxic epidermal necrolysis in a patient with post-menopausal osteoporosis," Osteoporosis International, vol. 20, no. 1, pp. 161-162, 2009.

[57] M. Pilmane, K. Salma-Ancane, D. Loca, J. Locs, and L. Berzina-Cimdina, "Strontium and strontium ranelate: historical review of some of their functions," Materials Science and Engineering: C, vol. 78, pp. 1222-1230, 2017.
[58] S. Bose, G. Fielding, S. Tarafder, and A. Bandyopadhyay, "Trace element doping in calcium phosphate ceramics to understand osteogenesis and angiogenesis," Trends in Biotechnology, vol. 18, pp. 1199-1216, 2013.

[59] S. Zhang, Y. Dong, M. Chen et al., "Recent developments in strontium-based biocomposites for bone regeneration," Journal of Artificial Organs, vol. 23, no. 3, pp. 191-202, 2020.

[60] P. J. Marie, "Strontium ranelate: a physiological approach for optimizing bone formation and resorption," Bone, vol. 38, no. 2, pp. 10-14, 2006.

[61] A. S. Hurtel-Lemaire, R. Mentaverri, A. Caudrillier et al., "The calcium-sensing receptor is involved in strontium ranelate-induced osteoclast apoptosis. New insights into the associated signaling pathways," Journal of Biological Chemistry, vol. 284, pp. 575-584, 2008.

[62] S. Takaoka, T. Yamaguchi, S. Yano, M. Yamauchi, and T. Sugimoto, "The calcium-sensing receptor $(\mathrm{CaR})$ is involved in strontium ranelate-induced osteoblast differentiation and mineralization," Hormone and Metabolic Research, vol. 42, no. 9, pp. 627-631, 2010.

[63] F. Yang, D. Yang, J. Tu, Q. Zheng, L. Cai, and L. Wang, "Strontium enhances osteogenic differentiation of mesenchymal stem cells and in vivo bone formation by activating Wnt/catenin signaling," Stem Cells, vol. 29, no. 6, pp. 981-991, 2011.

[64] B. Ma, Q. Zhang, D. Wu et al., "Strontium fructose 1,6diphosphate prevents bone loss in a rat model of postmenopausal osteoporosis via the OPG/RANKL/RANK pathway," Acta Pharmacologica Sinica, vol. 33, no. 4, pp. 479-489, 2012.

[65] L. Cianferotti, F. D'asta, and M. L. Brandi, “A review on strontium ranelate long-term antifracture efficacy in the treatment of postmenopausal osteoporosis," Therapeutic Advances in Musculoskeletal Disease, vol. 5, no. 3, pp. 127-139, 2013.

[66] L. Kyllönen, M. D’Este, M. Alini, and D. Eglin, "Local drug delivery for enhancing fracture healing in osteoporotic bone," Acta Biomaterialia, vol. 11, pp. 412-434, 2015.

[67] S. Pors Nielsen, "The biological role of strontium," Bone, vol. 35, no. 3, pp. 583-588, 2004.

[68] W. T. Su, P. S. Wu, and T. Y. Huang, "Osteogenic differentiation of stem cells from human exfoliated deciduous teeth on poly( $\varepsilon$-caprolactone) nanofibers containing strontium phosphate," Materials Science and Engineering: C, vol. 46, pp. 427-434, 2015.

[69] S. R. K. Meka, S. Jain, and K. Chatterjee, "Strontium eluting nanofibers augment stem cell osteogenesis for bone tissue regeneration," Colloids Surfaces B Biointerfaces, vol. 146, pp. 649-656, 2016.

[70] X. Han, X. Zhou, K. Qiu et al., "Strontium-incorporated mineralized PLLA nanofibrous membranes for promoting bone defect repair," Colloids Surfaces B Biointerfaces, vol. 179, pp. 363-373, 2019.

[71] G. Kumar, C. K. Tison, K. Chatterjee et al., "The determination of stem cell fate by 3D scaffold structures through the control of cell shape," Biomaterials, vol. 32, pp. 9188-9196, 2011.

[72] C. Xie, D. Reynolds, H. Awad et al., "Structural bone allograft combined with genetically engineered mesenchymal stem cells as a novel platform for bone tissue engineering," Tissue Engineering, vol. 13, no. 3, pp. 435-445, 2007.

[73] X. Wu, W. Shi, and X. Cao, "Multiplicity of BMP signaling in skeletal development," Annals of the New York Academy of Sciences, vol. 1116, no. 1, pp. 29-49, 2007. 
[74] C. Maes, T. Kobayashi, M. K. Selig et al., "Osteoblast precursors, but not mature osteoblasts, move into developing and fractured bones along with invading blood vessels," Developmental Cell, vol. 19, no. 2, pp. 329-344, 2010.

[75] Y. Zhang, L. K. Yu, and N. Xia, "Evaluation of serum and pleural levels of endostatin and vascular epithelial growth factor in lung cancer patients with pleural effusion," Asian Pacific Journal of Tropical Medicine, vol. 5, no. 3, pp. 239242, 2012.

[76] A. Javed, J. S. Bae, F. Afzal et al., "Structural coupling of Smad and Runx2 for execution of the BMP2 osteogenic signal," The Journal of Biological Chemistry, vol. 283, no. 13, pp. 84128422, 2008.

[77] P. Dy, W. Wang, P. Bhattaram et al., "Sox9 directs hypertrophic maturation and blocks osteoblast differentiation of growth plate chondrocytes," Developmental Cell, vol. 22, no. 3, pp. 597-609, 2012.

[78] M. Schumacher, A. Lode, A. Helth, and M. Gelinsky, "A novel strontium(II)-modified calcium phosphate bone cement stimulates human-bone-marrow-derived mesenchymal stem cell proliferation and osteogenic differentiation in vitro," Acta Biomaterialia, vol. 9, no. 12, pp. 9547-9557, 2013.

[79] J. Wang, X. Wang, Z. Sun et al., "Stem cells from humanexfoliated deciduous teeth can differentiate into dopaminergic neuron-like cells," Stem Cells and Development, vol. 19, no. 9, pp. 1375-1383, 2010.

[80] M. V. Jose, V. Thomas, K. T. Johnson, D. R. Dean, and E. Nyairo, "Aligned PLGA HA nanofibrous nanocomposite scaffolds for bone tissue engineering," Acta Biomaterialia, vol. 5, no. 1, pp. 305-315, 2009.

[81] S. Peng, X. S. Liu, T. Wang et al., "In vivo anabolic effect of strontium on trabecular bone was associated with increased osteoblastogenesis of bone marrow stromal cells," Journal of Orthopaedic, vol. 28, no. 9, pp. 1208-1214, 2010.

[82] K. Madhavan Nampoothiri, N. R. Nair, and R. P. John, “An overview of the recent developments in polylactide (PLA) research," Bioresource Technology, vol. 101, no. 22, pp. 8493-8501, 2010.

[83] A. Martins, A. R. C. Duarte, S. Faria, A. P. Marques, R. L. Reis, and N. M. Neves, "Osteogenic induction of hBMSCs by electrospun scaffolds with dexamethasone release functionality," Biomaterials, vol. 31, no. 22, pp. 5875-5885, 2010.

[84] B. Gupta, N. Revagade, and J. Hilborn, "Poly(lactic acid) fiber: an overview," Progress in Polymer Science, vol. 32, no. 4, pp. 455-482, 2007.

[85] G. Sui, X. Yang, F. Mei et al., "Poly-L-lactic acid/hydroxyapatite hybrid membrane for bone tissue regeneration," Journal of Biomedical Materials Research Part A, vol. 82A, pp. 445454, 2007.

[86] L. E. Charles, E. R. Kramer, M. T. Shaw, J. R. Olson, and M. Wei, "Self-reinforced composites of hydroxyapatitecoated PLLA fibers: fabrication and mechanical characterization," Journal of the Mechanical Behavior of Biomedical Materials, vol. 17, pp. 269-277, 2013.

[87] S. Bhakta, P. E. Faira, L. A. Salata et al., "Determination of relative in vivo osteoconductivity of modified potassium fluorrichterite glass-ceramics compared with 45S5 bioglass," Journal of Materials Science Materials in Medicine, vol. 23, no. 10, pp. 2521-2529, 2012.

[88] J. S. Fernandes, P. Gentile, M. Martins et al., "Reinforcement of poly-L-lactic acid electrospun membranes with strontium borosilicate bioactive glasses for bone tissue engineering," Acta Biomaterialia, vol. 44, pp. 168-177, 2016.

[89] L. Chen, H. Mazeh, A. Guardia et al., "Sustained release of strontium $\left(\mathrm{Sr}^{2+}\right)$ from polycaprolactone/poly (D,L-lactideco-glycolide)-polyvinyl alcohol coaxial nanofibers enhances osteoblastic differentiation," Journal of Biomaterials Applications, vol. 34, no. 4, pp. 533-545, 2019.

[90] A. B. Lino, A. D. McCarthy, and J. M. Fernández, "Evaluation of strontium-containing PCL-PDIPF scaffolds for bone tissue engineering: in vitro and in vivo studies," Annals of Biomedical Engineering, vol. 47, no. 3, pp. 902-912, 2019.

[91] S. W. Tsai, W. X. Yu, P. A. Hwang et al., "Fabrication and characterization of strontium-substituted hydroxyapatite$\mathrm{CaO}-\mathrm{CaCO} 3$ nanofibers with a mesoporous structure as drug delivery carriers," Pharmaceutics, vol. 10, no. 4, p. 179, 2018.

[92] S. W. Tsai, W. X. Yu, P. A. Hwang, Y. W. Hsu, and F. Y. Hsu, "Fabrication and characteristics of PCL membranes containing strontium-substituted hydroxyapatite nanofibers for guided bone regeneration," Polymers, vol. 11, no. 11, p. 1761, 2019.

[93] S. W. Tsai, F. Y. Hsu, and P. L. Chen, "Beads of collagennanohydroxyapatite composites prepared by a biomimetic process and the effects of their surface texture on cellular behavior in MG63 osteoblast-like cells," Acta Biomaterialia, vol. 4, no. 5, pp. 1332-1341, 2008.

[94] J. Caverzasio, "Strontium ranelate promotes osteoblastic cell replication through at least two different mechanisms," Bone, vol. 42, no. 6, pp. 1131-1136, 2008.

[95] P. F. Sharkey, P. M. Lichstein, C. Shen, A. T. Tokarski, and J. Parvizi, "Why are total knee arthroplasties failing today-has anything changed after 10 years?," The Journal of Arthroplasty, vol. 29, pp. 1774-1778, 2013.

[96] W. Song, J. Seta, L. Chen et al., "Doxycycline-loaded coaxial nanofiber coating of titanium implants enhances osseointegration and inhibits Staphylococcus aureus infection," Biomedical Materials, vol. 12, article 045008, 2012.

[97] J. Wang, A. Shah, and X. Yu, "The influence of fiber thickness, wall thickness and gap distance on the spiral nanofibrous scaffolds for bone tissue engineering," Materials Science and Engineering: C, vol. 31, no. 1, pp. 50-56, 2011.

[98] T. Kohgo, Y. Yamada, K. Ito et al., "Bone regeneration with self-assembling peptide nanofiber scaffolds in tissue engineering for osseointegration of dental implants," The International Journal of Periodontics \& Restorative Dentistry, vol. 31, no. 4, pp. e9-16, 2011.

[99] Z. Huang, R. H. Daniels, R. J. Enzerink, V. Hardev, V. Sahi, and S. B. Goodman, "Effect of nanofiber-coated surfaces on the proliferation and differentiation of osteoprogenitors in vitro," Tissue Engineering Part A, vol. 14, no. 11, pp. 1853-1859, 2008.

[100] J. M. Gluck, P. Rahgozar, N. P. Ingle et al., "Hybrid coaxial electrospun nanofibrous scaffolds with limited immunological response created for tissue engineering," Journal of Biomedical Materials Research Part B: Applied Biomaterials, vol. 99, no. B, pp. 180-190, 2011.

[101] L. Hench and J. Wilson, "Surface-active biomaterials," Science, vol. 226, no. 4675, pp. 630-636, 1984.

[102] Y. Li, B. Li, G. Xu et al., "A feasible approach toward bioactive glass nanofibers with tunable protein release kinetics for bone scaffolds," Colloids Surfaces B Biointerfaces, vol. 122, pp. 785791, 2014. 
[103] S. K. Boda, G. Thrivikraman, B. Panigrahy, D. D. Sarma, and B. Basu, "Competing roles of substrate composition, microstructure, and sustained strontium release in directing osteogenic differentiation of hMSCs," ACS Applied Materials \& Interfaces, vol. 9, pp. 19389-19408, 2016.

[104] L. Weng, S. K. Boda, M. J. Teusink, F. D. Shuler, X. Li, and J. Xie, "Binary doping of strontium and copper enhancing osteogenesis and angiogenesis of bioactive glass nanofibers while suppressing osteoclast activity," ACS Applied Materials \& Interfaces, vol. 9, no. 29, pp. 24484-24496, 2017.

[105] S. V. Fridrikh, J. H. Yu, M. P. Brenner, and G. C. Rutledge, "Controlling the fiber diameter during electrospinning," Physical Review Letters, vol. 90, 2003.

[106] S. Hesaraki, M. Alizadeh, H. Nazarian, and D. Sharifi, "Physico-chemical and in vitro biological evaluation of strontium/calcium silicophosphate glass," Journal of Materials Science Materials in Medicine, vol. 21, no. 2, pp. 695-705, 2010.

[107] S. Islam, F. Hassan, G. Tumurkhuu et al., "Bacterial lipopolysaccharide induces osteoclast formation in RAW 264.7 macrophage cells," Biochemical and Biophysical Research Communications, vol. 360, no. 2, pp. 346-351, 2007.

[108] M. Roy and S. Bose, "Osteoclastogenesis and osteoclastic resorption of tricalcium phosphate: effect of strontium and magnesium doping," Journal of Biomedical Materials Research Part A, vol. 100, no. A, pp. 2450-2461, 2012.

[109] M. M. Echezarreta-López and M. Landin, "Using machine learning for improving knowledge on antibacterial effect of bioactive glass," International Journal of Pharmaceutics, vol. 453, no. 2, pp. 641-647, 2013.

[110] L. L. Hench, "The story of Bioglass ${ }^{\circledR}$," Journal of Materials Science. Materials in Medicine, vol. 17, no. 11, pp. 967-978, 2006.

[111] M. M. Echezarreta-López, T. De Miguel, F. Quintero, J. Pou, and M. Landín, "Fabrication of Zn-Sr-doped laser-spinning glass nanofibers with antibacterial properties," Journal of Biomaterials Applications, vol. 31, pp. 819-831, 2016.

[112] H. Doweidar, "Density-structure correlations in silicate glasses," Journal of Non-Crystalline Solids, vol. 249, no. 2-3, pp. 194-200, 1999.

[113] L. Gu, X. He, and Z. Wu, "Mesoporous hydroxyapatite: preparation, drug adsorption, and release properties," Materials Chemistry and Physics, vol. 148, no. 1-2, pp. 153-158, 2014.

[114] Y. J. Shyong, M. H. Wang, L. W. Kuo et al., "Mesoporous hydroxyapatite as a carrier of olanzapine for long-acting antidepression treatment in rats with induced depression," Journal of Controlled Release, vol. 255, pp. 62-72, 2017.

[115] T. A. Kuriakose, S. N. Kalkura, M. Palanichamy et al., "Synthesis of stoichiometric nano crystalline hydroxyapatite by ethanol-based sol-gel technique at low temperature," Journal of Crystal Growth, vol. 263, no. 1-4, pp. 517-523, 2004.

[116] M. H. Fathi, A. Hanifi, and V. Mortazavi, "Preparation and bioactivity evaluation of bone-like hydroxyapatite nanopowder," Journal of Materials Processing Technology, vol. 202, no. 1-3, pp. 536-542, 2008.

[117] P. Kanchana and C. Sekar, "Influence of strontium on the synthesis and surface properties of biphasic calcium phosphate (BCP) bioceramics," Journal of Applied Biomaterials \& Biomechanics, vol. 8, no. 3, pp. 153-158, 2010. 